J. Comp. Physiol. 141 417-423 (1981)

\title{
Catabolic Enzyme Activities in Relation to Premigratory Fattening and Muscle Hypertrophy in the Gray Catbird (Dumetella carolinensis)
}

\author{
Richard L. Marsh* \\ Division of Biological Sciences, The University of Michigan, Ann Arbor, Michigan 48109, USA \\ Accepted December 8, 1980
}

\begin{abstract}
Summary. The flight muscles of the gray catbird $(D u$ metella carolinensis) were examined to determine if short term adjustments occur in the activity of key catabolic enzymes during preparation for long distance migration. The aerobic capacity of the pectoralis muscle as indicated by citrate synthase activity (CS) is among the highest reported for skeletal muscle $\left(200 \mu\right.$ moles [min $\cdot \mathrm{g}$ fresh mass] ${ }^{-1}$ at $25^{\circ} \mathrm{C}$ ). The mass specific aerobic capacity as indicated by CS activity or cytochrome $c$ concentration does not change during premigratory fattening (Fig. 2) or in relation to the muscle hypertrophy that occurs concomitantly. The maintenance of mass specific aerobic capacity indicates that the total aerobic capacity increases in proportion to the increase in muscle size. The augmented potential for total aerobic power output is considered an adaptation to meet the increased power requirements of flight due to the increased body mass. Additionally, the capacity to oxidize fatty acids, as indicated by $\beta$-hydroxyacyl-CoA dehydrogenase activity, approximately doubles during premigratory fattening (from 35 to $70 \mu$ moles [min $\cdot \mathrm{g}$ fresh mass] ${ }^{-1}$ at $25^{\circ} \mathrm{C}$; Fig. $1 \mathrm{~A}$ ). This adaptation should favor fatty acid oxidation, thereby sparing carbohydrate and prolonging endurance. The activity of phosphofructokinase, a key glycolytic enzyme, does not change before migration.
\end{abstract}

\section{Introduction}

The relative activities of catabolic enzymes within various skeletal muscles are adapted to the frequency

* Present address: Department of Developmental and Cell Biology, University of California, Irvine, California 92717, USA

Abbreviations: $C P T$ carnitine palmitoyl transferase; $C S$ citrate synthase; HOAD $\beta$-hydroxyacyl-COA-dehydrogenase; $P F K$ phosphofructokinase of muscle activity and the type of fuel used (Beenakkers 1969; Bass et al. 1969; Crabtree and Newsholme 1972a, b, 1975; Staudte and Pette 1972; Alp et al. 1976). These enzymatic specializations result from a combination of long-term evolutionary adaptations and short-term adjustments. For example, evolutionary adaptation of muscles for sustained use is reflected in high activities of enzymes in the citric acid cycle and electron transport system (see Crabtree and Newsholme 1975). Similarly, in the short-term, individual muscles respond to increases or decreases in the frequency of use with corresponding increases or decreases in aerobic capacity (see Holloszy and Booth 1976, for a review). However, our knowledge of the nature and importance of these short-term adjustments in free-living animals is severely limited.

Migration by various species of birds represents a dramatic instance of a seasonal change in use of specific muscles. Migratory birds probably exceed all other vertebrates in the duration of locomotor activity undertaken at high levels of metabolic rate. Some small birds cover distances of up to $4,000 \mathrm{~km}$, maintaining continuous flapping flight for more than $48 \mathrm{~h}$ (see Williams et al. 1977). The levels of metabolic effort during such flights are estimated to be 5 to 10 times the standard metabolic rate. (The calculated value depends on the species and amount of fat reserve carried [see Pennycuick 1975]). With the possible exception of some insectivorous birds (e.g., swifts) which may fly continuously for long periods at all seasons, these migratory flights greatly exceed in duration and energetic cost the flights undertaken during non-migratory periods. Long-distance migration poses two interacting problems related to the capacities of the flight muscles. 1) Premigratory fattening, which provides the fuel reserve necessary for the flight, greatly increases the body weight and thus the mechanical power output required from the flight muscles. 2) The long duration of the flight requires 
that the muscles maintain oxygen and fuel homeostasis to prevent exhaustion. These two problems are particularly intriguing because they combine the elements of 'power training' and 'endurance training' which are usually considered separately in exercise studies involving laboratory mammals and man.

I have examined the flight muscles of the gray catbird (Dumetella carolinensis) to determine if shortterm adjustments occur which would tend to alleviate these problems (Marsh 1979). Catbirds breed over an extensive area of eastern North America (A.O.U. Checklist, 1957) and individuals migrate varying distances wintering primarily in the Carribean islands, Central America, and in a narrow strip along the Gulf Coast of United States. At least a portion of the population apparently migrates across the Gulf of Mexico (Stevenson 1957; Marsh 1979). This transGulf route, which is used by numerous North American migrants, involves a flight of a least $1,000 \mathrm{~km}$. Flying at its estimated maximum-range velocity $\left(47 \mathrm{~km} \cdot \mathrm{h}^{-1}\right)$, a catbird would require $21 \mathrm{~h}$ to travel this distance.

The pectoralis muscles of the catbird have been shown to hypertrophy in response to increases in body mass (Marsh 1979). This adaptation is probably general among those flying birds that undergo large changes in mass as adults (see Fry et al. 1972; Marsh and Storer, unpublished data; Marsh 1979) and represents a natural analog of power training. The data in this report demonstrate that the pectoralis muscles maintain a very high aerobic capacity during this hypertrophy and additionally show an increase in a key enzyme in the $\beta$-oxidative pathway for degradation of fatty acids. This shift in enzyme activity presumably reflects an augmented capacity of the migrants to oxidize free fatty acids, which should favor endurance during long flights.

\section{Materials and Methods}

\footnotetext{
Animals

Catbirds were mist-netted near Ann Arbor, Washtenaw County, Michigan, and Gainesville, Alachua County, Florida. Michigan birds were captured during Spring through early Fall, 1977 and represent summer residents and early fall migrants. Florida captures took place in the falls of 1976, 1977 and were migrants or, perhaps in a few cases, early winter residents. The forty animals used had a mean mass of $38.36 \pm 0.66$ g (S.E.M.) with a range of 29.6 to $49.0 \mathrm{~g}$.

\section{Muscle and Body Composition}

Animals were sacrificed by decapitation and the left pectoralis and supracoracoideus muscles quickly removed for measurement of enzyme activities or cytochrome $c$ concentration (see below). The heart was also removed from 5 birds for measurement of cytochrome $c$ content. The remainder of the carcass was placed
}

in a tightly sealed plastic bag and refrigerated. Within $24 \mathrm{~h}$ the right pectoralis and supracoracoideus muscles were removed and weighed to the nearest $0.1 \mathrm{mg}$ to determine fresh mass. Birds were sexed by examination of the gonads and aged by the extent of skull pneumatization (juvenile $=$ partially ossified; adult $=$ completely ossified). The muscles and the carcass were subjected to compositional analysis to determine water, fat (neutral lipid), and lean dry mass according to the methods described in Marsh (1979; see also Carey et al. 1978).

\section{Enzyme Activities and Cytochrome c Concentration}

Muscles used for the measurement of enzyme activities were divided in half. One half was used for the determination of phosphofructokinase activity (PFK, E.C. 2.4.1.1) and the other half for determination of citrate synthease activity (CS, E.C. 4.1.3.7) and $\beta$-hydroxyacyl-CoA dehydrogenase activity (HOAD, E.C. 1.1.1.35). Each half was weighed and homogenized in either 10 volumes (pectoralis muscle) or 20 volumes (supracoracoideus muscle) of buffer in a hand-held glass-glass homogenizer maintained on ice. For analysis of PFK, the homogenizing buffer contained $50 \mathrm{mM}$ Tris- $\mathrm{HCl}$, $1 \mathrm{mM}$ EDTA, and $5 \mathrm{mM} \mathrm{MgSO}_{4}$ at $\mathrm{pH}$ 8.2. For anaiysis of $\mathrm{CS}$ and HOAD, the medium contained $100 \mathrm{mM}$ phosphate, and $2 \mathrm{mM}$ EDTA at pH 7.3. The homogenates were sonicated for three, 15-s intervals and stored at $0{ }^{\circ} \mathrm{C}$ until the enzyme assays were performed. Control assays indicated that there were no systematic differences in enzyme activities between the halves of each muscle and no loss of activity over $8 \mathrm{~h}$ of storage at $0^{\circ} \mathrm{C}$.

Spectrophotometric assays were performed on the crude homogenates at $25^{\circ} \mathrm{C}$ using a Zeiss PMQ3 spectrophotometer at 340 (PFK and HOAD) or $412 \mathrm{~nm}$ (CS). Phosphofructokinase was assayed by a modification of the procedures of Opie and Newsholme (1967) and Mansour (1966). The assay medium contained $50 \mathrm{mM}$ Tris- $\mathrm{HCl}, 5 \mathrm{mM} \mathrm{MgCl}, 200 \mathrm{mM} \mathrm{KCl}, 30 \mathrm{mM} \mathrm{KCN}$, $1 \mathrm{mM}$ ATP, $2 \mathrm{mM}$ AMP $, 0.1 \mathrm{mM} \mathrm{NADH}, 10 \mu \mathrm{g}$ of $\alpha$-glycerophosphate dehydrogenase and triose isomerase, $50 \mu \mathrm{g}$ of aldolase, and $2 \mathrm{mM}$ fructose-6-phosphate at $\mathrm{pH} 8.2$ in a final volume of $1 \mathrm{ml}$. The CS assay medium was modified from those of Srere (1969) and Bass et al. (1969) and contained $100 \mathrm{mM}$ Tris-HCl, $2.5 \mathrm{mM}$ EDTA, $0.1 \mathrm{mM}$ 5,5'-dithiobis-(2-nitrobenzoic acid), $0.2 \mathrm{mM}$ acetyl-CoA, and $0.5 \mathrm{mM}$ oxaloacetate at $\mathrm{pH} 7.5$ in a final volume of $1 \mathrm{ml}$. For the assay of HOAD, the medium was modified from that of Bass et al. (1969) and contained $100 \mathrm{mM}$ triethanolamine- $\mathrm{HCl}, 5 \mathrm{mM}$ EDTA, $0.225 \mathrm{mM} \mathrm{NADH}_{2}$, and $0.1 \mathrm{mM}$ acetoacetyl-CoA at $\mathrm{pH} 7.0$ in a final volume of $1 \mathrm{ml}$. All activities measured were proportional to enzyme concentration and were measured at saturating substrate concentrations. Small but significant control activities were present in the HOAD assay in the absence of acetoacetyl-CoA, and these values were subtracted from the rate with substrate present. Duplicate assays were performed in each case and the results are reported as $\mu$ moles substrate used [min.g fresh mass] $]^{-1}$.

Cytochrome $c$ concentrations were measured on freshly dissected whole muscles or hearts according to the methods of Williams and Thorp (1969).

\section{Results}

Table 1 gives descriptive statistics on the maximal enzyme activities of catbird muscles obtained from the entire sample from Michigan and Florida. On a mass-specific basis, the pectoralis muscle has more than twice the activity of CS as the supracoracoideus muscle $(201 \pm 8.2$ and $90.3 \pm 4.51 \mu$ moles [min $\cdot g$ fresh mass $]^{-1}$, respectively). The activity of HOAD in the pectoralis muscle is also more than double that in 
Table 1. Enzyme activities in the flight muscles of the catbird

\begin{tabular}{llllll}
\hline Muscle & Enzyme & $N$ & $\begin{array}{l}\text { Mean } \\
\text { activity } \\
\mu \text { moles } \\
{[\mathrm{min} \cdot \mathrm{g}]^{-1}}\end{array}$ & Range & S.E. \\
\hline Pectoralis & CS & 26 & 201 & $131-292$ & 8.20 \\
& HOAD & 28 & 52.4 & $21.8-103$ & 3.20 \\
& PFK & 20 & 56.2 & $40.7-69.9$ & 1.71 \\
Supra- & CS & 25 & 90.3 & $55.8-144$ & 4.50 \\
coracoideus & HOAD & 26 & 21.1 & $6.71-35.2$ & 1.28 \\
& PFK & 18 & 47.2 & $16.1-78.6$ & 4.16 \\
\hline
\end{tabular}

a Activity per gram fresh mass

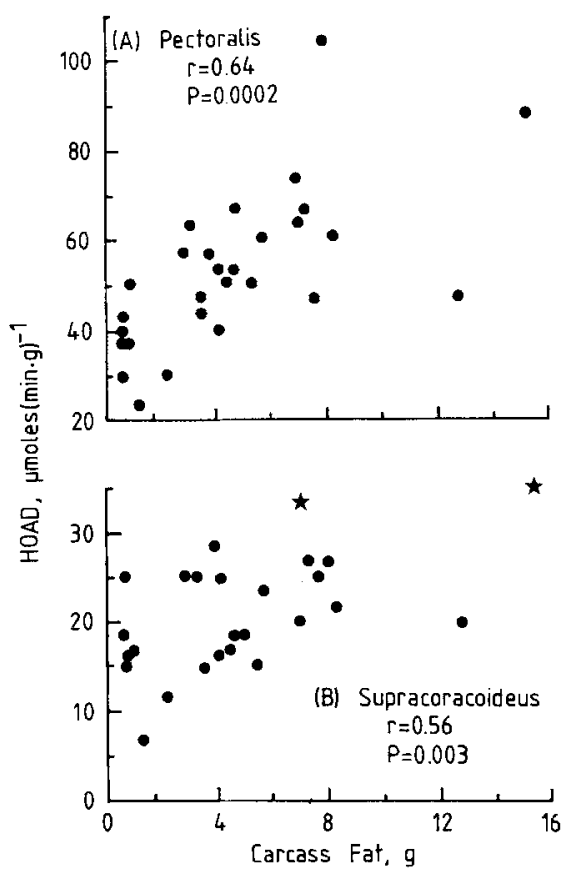

Fig. 1 A, B. Relation between HOAD activity in the flight muscles of the catbird and carcass fat. A Pectoralis. B Supracoracoideus. See text for comment on the starred values

the supracoracoideus muscle $(52.4 \pm 3.21$ and $21.1 \pm$ $1.28 \mu$ moles [min $\cdot \mathrm{g}$ fresh mass $]^{-1}$, respectively). The two muscles do not have significantly different PFK activities although the PFK activity of the supracoracoideus muscle is significantly more variable $(F=$ 5.33, $P<0.0001, d f=36$ ).

The mass of the pectoralis muscle among the individuals used for the measurement of enzyme activities ranged from 3.68 to $5.40 \mathrm{~g}$ and is significantly correlated with body mass, which ranged from 29.6 to $49.0 \mathrm{~g}(r=0.79, P<0.0001, n=28)$. (Analysis of covariance indicated that this relationship is not significantly different from that in a larger sample of catbirds from Michigan and Florida (Marsh 1979)). No

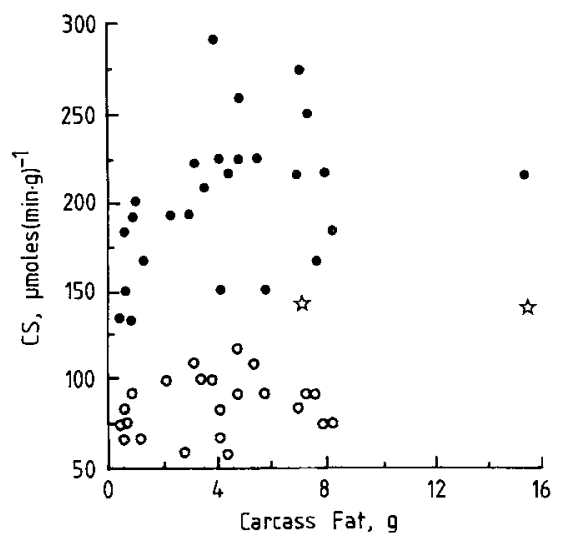

Fig. 2. Relation between CS activity in the flight muscles of the catbird and carcass fat. Closed circles $=$ pectoralis, $r=0.38, P>$ 0.05 ; open circles and stars $=$ supracoracoideus, $r=0.53, P=0.0058$. See text for comment on starred values

correlation exists between the activity of any of the enzymes and the mass of either the pectoralis or supracoracoideus muscles $(|r|<0.27, P>0.21)$ or between any of the enzymes and the carcass lean dry mass $(|r|<0.15, P>0.46)$. However, some significant positive correlations exist between enzymatic activity and carcass fat content. The HOAD activities in the pectoralis and supracoracoideus muscles are significantly related to carcass fat (Fig. $1 ; r=0.64, P=$ 0.0002 and $r=0.56, P=0.0029$, respectively). In addition, CS activity in the supracoracoideus muscle is significantly correlated with carcass fat (Fig. 2; $r=$ $0.54, P=0.0058$ ). Note that the correlation of carcass fat with supracoracoideus $\mathrm{CS}$ and HOAD is due largely to two animals with unusually high values for both enzymes (Fig. 1 and 2, starred values). PFK activity from either muscle is not significantly correlated with carcass fat $(P>0.05)$. The only significant correlations between the activities of the various enzymes are between CS and HOAD activities in both muscles $(r=0.50, P=0.0097$ and $r=0.44, P=0.028$ in the pectoralis and supracoracoideus muscles, respectively) and between the HOAD activity of the pectoralis muscle and HOAD activity in the supracoracoideus muscle $(r=0.754, P<0.0001)$. No sex or age related differences exist in the activity of any enzyme (11 males, 16 females; Student's $t$-tests, $P>0.2 ; 16$ juveniles, 10 adults; Student's $t$-tests and analysis of covariance, $P>0.23$ ).

The cytochrome $c$ concentrations in the pectoralis muscle and the heart both approximate $45 \mathrm{nmole} \cdot \mathrm{g}^{-1}$, whereas the supracoracoideus muscle has less than half this concentration (Table 2). The muscle cytochrome $c$ concentrations are not significantly correlated with muscle mass or carcass fat content $(|r|<0.40$, $P>0.46)$. 
Table 2. Cytochrome $c$ concentrations in the flight muscles and heart of the catbird

\begin{tabular}{lrlll}
\hline Tissue & $N$ & $\begin{array}{l}\text { Mean } \\
\text { concentration } \\
\mu \text { moles } \cdot \mathrm{g}^{-1}\end{array}$ & Range & S.E. \\
\hline Pectoralis & 12 & 45.6 & $29.9-59.2$ & 2.44 \\
Supracoracoideus & 12 & 20.9 & $13.9-27.5$ & 1.08 \\
Heart & 5 & 45.7 & $34.3-59.2$ & 5.04 \\
\hline
\end{tabular}

\section{Discussion}

Similar to other trans-Gulf migrants catbirds attain maximum levels of fat content near the Gulf of Mexico (Marsh 1979; cf. Caldwell et al. 1963). A similar phenomenon is evident in Old World migrants that cross the Sahara Desert and Mediterranean Sea (Fry et al. 1970). These birds evidently migrate overland in short flights, stopping en route to feed, until they near these geographical barriers. At this point they pause, feeding and gaining fat until sufficient reserves are accumulated to fly non-stop across the barriers. In the absence of specific information on the migratory status of any individual bird collected, it is reasonable to use the carcass fat content as an index of the readiness of the bird to undertake this long flight.

One way in which the flight muscles adapt during fattening is by increasing in size (Marsh 1979; this study). This adaptation is specific to the depressors of the wings, the pectoralis muscles. The asymmetry in the response of the two muscles is understandable since little or no aerodynamic power is produced during the upstroke in most birds (see Lighthill 1977). Without the observed increase in size, the pectoralis muscles would have to operate at or near their estimated maximum aerobic power outputs to produce the power required to fly (Marsh 1979). Because the mass specific aerobic capacity is maintained (Fig. 2; see below), the increase in size should contribute to endurance by allowing the muscles to operate at submaximal levels of oxygen consumption.

Endurance will be additionally related to the capacities for maintaining homeostasis in fuel delivery and oxidation. Material balance studies have demonstrated that fat is the major substrate used during the migratory flights of birds (Berthold 1975). However, studies of mammalian exercise have implicated carbohydrate as the limiting fuel for endurance exercise, even when fatty acids are the major fuel (Bergstrom and Hultman 1967; Paul and Holmes 1975). This limitation exists because oxidation of carbohydrate increases proportionally to the increase in metabolic rate (Paul and Holmes 1975) and body stores of carbohydrate and gluconeogenic capacities are lim- ited (see Newsholme and Start 1973). Carbohydrate reserves are similarly small in the catbird (Marsh 1979). Therefore, adjustments producing increased oxidation of fatty acids and reduced oxidation of carbohydrate may be an important factor in increasing endurance (see Holloszy and Booth 1976).

\section{Enzymatic Activity as an Indicator of Maximum Metabolic Flux}

The relative ease of measurements of enzyme activity, as compared to direct assessment of metabolic flux has made use of indicator enzymes a common method for assessing the metabolic capacities of a tissue. The interpretation of the activities measured depends, of course, on how well the enzymes chosen indicate the maximum flux through the pathways of interest. The obvious advantages of measuring the activities of rate limiting enzymes (see Crabtree and Newsholme 1975) is tempered by the difficulty of determining the rate limiting steps in vivo and in defining the optimum in vitro conditions for the enzyme assays. For intraspecific studies, such as the present one, the most desirable attribute of the enzymes to be measured is that their activities should change within individual muscles in a manner correlated with the tissue capacity for substrate use.

\section{Aerobic Capacity}

Citrate synthase has been used in this study to indicate the capacity for oxidation of acetyl-CoA in the citric acid cycle. I have supplemented the data obtained with this indicator of aerobic capacity with measurements of cytochrome $c$, a key protein in electron transport. Regulation of the citric acid cycle in muscle is currently open to question (Alp et al. 1976; Williamson 1979). However, measurements using isolated, perfused rat hearts indicate that the first steps of the cycle, including the CS step, are regulated in a concerted fashion (Williamson 1979). Further support for the use of CS and cytochrome $c$ as indicators of aerobic capacity comes from work on endurancetrained rats. The proportionate increases in CS activity and cytochrome $c$ concentration in hind-limb muscles correlate well with the increase in the tissue's ability to oxidize substrates and the endurance of the whole animal (Holloszy and Booth 1975).

The aerobic capacity, as indicated by the CS activity and cytochrome $c$ concentration, of the pectoralis muscle of the catbird is approximately double that of the supracoracoideus muscle (Tables 1 and 2). A similar difference between these two muscles has been noted in other birds on the basis of succinic dehydrogenase activities (George and Talesara 1961), and correlates with the greater role of the pectoralis mus- 
cle in the production of power for sustained flight (Lighthill 1977). The CS activity of catbird pectoralis muscle is the highest reported for any vertebrate skeletal muscle, and is as high as the activities found in the flight muscles of some insects (Alp et al. 1976). The high CS activity correlates well with the uniformly high oxidative capacity of the fibers as judged histochemically (Marsh 1979). The CS activity of pigeon pectoralis muscle, often used as an example of high oxidative muscle, is approximately half that of the catbird (Alp et al. 1976). The lower activity in the pigeon may be due to a lower proportion of high oxidative fibers, as the pectoralis muscle of the pigeon is approximately $50 \%$ by volume low oxidative fibers (estimated from data in George and Berger 1966). The CS activity in the pectoralis muscle of two other small, wild passerines is in the same range as that of the catbird, 192 and $201 \mu$ moles [min.g fresh mass] ${ }^{-1}$ for the 25 -g house sparrow (Passer domesticus) and the 13-g American goldfinch (Spinus tristis), respectively (unpublished observations). The $\mathrm{CS}$ activities (at $25^{\circ} \mathrm{C}$ ) in the flight muscles (pectoralis major) of several species of bats ranging in body mass from 5 to $85 \mathrm{~g}$ are also approximately $200 \mu$ moles [min. $\mathrm{g}$ fresh mass] ${ }^{-1}$ (M. Yacoe, personal communication). The possibility exists that this activity represents the upper limit of the aerobic capacity of vertebrate skeletal muscle.

The mass specific aerobic capacity of the catbirds' flight muscles (based on both CS activity and cytochrome $c$ concentration) does not change during premigratory fattening (Fig. 2) and does not correlate with muscle size. This maintenance of aerobic capacity is similar to the situation found in exercise-induced hypertrophy of the mammalian heart (Oscai et al. 1971) and contrasts with the decreases in aerobic capacity found in skeletal muscles which hypertrophy due to mechanical overload (Gonyea and Bonde-Petersen 1978; MacDougall et al. 1979). However, catbirds exercise regularly during their daily activities and overload of skeletal muscles accompanied by exercise apparently leads to hypertrophy with no decrease in aerobic capacity (cf. Baldwin et al. 1977).

\section{$\beta$-Oxidative Capacity}

The activity of HOAD has been used previously to indicate tissue capacity to oxidize fatty acids, based on the constant proportion concept and the correlation between HOAD activity and the capacity of isolated mitochondria to oxidize fatty acids (Beenakkers et al. 1967; Bass et al. 1969; Beenakkers 1969; Staudte and Pette 1972). Crabtree and Newsholme (1972b, 1975) have suggested carnitine palmitoyltransferase (CPT) activity be used instead of HOAD

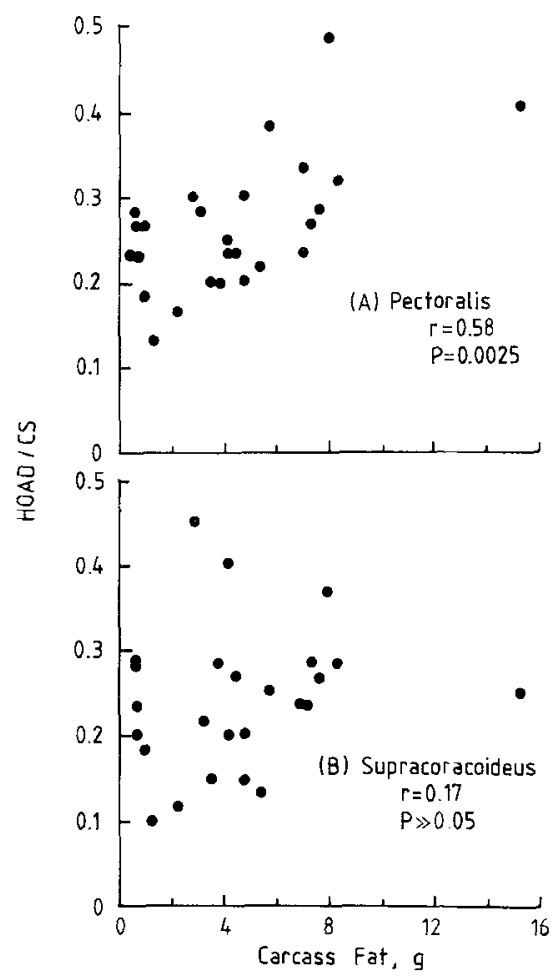

Fig. $3 \mathrm{~A}, \mathbf{B}$. The ratio of HOAD activity to CS activity in the flight muscles of the catbird as a function of carcass fat. A Pectoralis. B Supracoracoideus

activity because CPT activities are more likely to be rate limiting. However, HOAD activity may be regulated by the oxidation-reduction state of the nicotinamide nucleotides and may be rate limiting under in vivo conditions (Hochachka et al. 1977). Further, the age-related decrease in the capacity of rat heart mitochondria to oxidize long chain fatty acids is associated with a comparable decrease in HOAD, but no change in CPT (Hansford 1978). Thus, HOAD activities appear to be a reasonable relative indicator of the ability to oxidize fatty acids.

Measurements of HOAD activity indicate that the capacity of the pectoralis muscle to oxidize fatty acids approximately doubles in association with increased levels of body fat during the fall migratory period (Fig. 1A). Since the activities of CS and HOAD (both mitochondrial enzymes) are often correlated (this study; Staudte and Pette 1972), it is useful to express the $\beta$-oxidative capacity of the muscle by using the ratio of HOAD to CS ( $\beta$-oxidative to aerobic capacities). In the pectoralis muscle, HOAD:CS increases significantly with increased levels of carcass fat (Fig. 3A; $r=0.58, P=0.0025, n=25$ ), whereas this ratio does not change significantly in the supracoracoideus muscle (Fig. 3B; $r=0.17, P=0.41, n=25$ ). A specific activation of the $\beta$-oxidative pathway ap- 
parently takes place in the pectoralis muscle, resulting in a change in mitochondrial enzyme composition as indicated by HOAD:CS. Because the proportion of various fiber types is constant during fattening (Marsh 1979), the change in this ratio must represent a change in mitochondrial composition within existing fiber types.

Many investigators consider an increased reliance on the oxidation of fatty acids to be a key factor in increasing endurance during mammalian training studies (see Holloszy and Booth 1976). However, during training the enzymes involved in the citric acid cycle and the degradation of fatty acids increase by similar amounts (Molé et al. 1971). Thus, in mammals the primary adjustment at the biochemical level is an increase in aerobic capacity, and it is unclear whether the decreased oxidation of carbohydrate after training (Henriksson 1977) is due to enzyme adaptations or extramuscular factors influencing substrate delivery, such as hormonal levels, the concentration of blood substrates (Rennie and Johnson 1974) or tissue vascularity (Andersen and Henriksson 1977).

The conclusion from enzyme activities that birds fattening for migration have increased capacities for the oxidation of fatty acids disagrees with the conclusions of George and Vallyathan (1964), based on the oxidation of butyrate by homogenates of the pectoralis muscles of rosy pastors (Sturnus roseus). However, the very low rates of fatty acid oxidation recorded in their study may have been due to methodological problems. A reexamination of the oxidation of substrates by the mitochondria of migratory birds, using improved techniques, would be of considerable interest.

\section{Glycolytic Capacity}

Compared to the citric acid cycle and $\beta$-oxidation of fatty acids, regulation of glycolysis is well established. Phosphofructokinase is accepted as the rate limiting enzyme in this pathway (Crabtree and Newsholme 1975) and has been used previously to indicate glycolytic capacity in various muscles (Crabtree and Newsholme 1972a).

The pectoralis and supracoracoideus muscles of the catbird have similar glycolytic capacities despite large differences in aerobic capacity. The greater variability in PFK activity in the supracoracoideus muscle as compared to the pectoralis muscle may be related to the greater individual variability in fiber type in the former muscle (Marsh 1979). The glycolytic capacity as indicated by PFK does not change during fattening or with increases in muscle size. However, the lack of change in PFK does not necessarily indicate that catbirds do not decrease their reliance on carbohydrate during migratory flights. Glycolysis is decreased during oxidation of fatty acids by allosteric regulation (see Williamson 1979) and carbohydrate oxidation may be regulated at other sites such as pyruvate dehydrogenase (Berger et al. 1976).

\section{Conclusions}

The catbird and other small birds have pectoralis muscles with the highest mass specific aerobic capacity (based on CS activity) reported for vertebrate muscle, and, perhaps not surprisingly, this capacity does not change in preparation for long distance migration. However, because the mass specific aerobic capacity remains constant while the muscles hypertrophy, the total aerobic capacity should increase proportional to the increase in muscle size ( $\sim 35 \%$; Marsh 1979). This increase in the capacity for total aerobic power output is probably crucial during the initial phase of the migratory flight because of the mass of stored fuel (fat) that must be carried. Additionally, the large increase in $\beta$-oxidative capacity (indicated by HOAD activity) may represent an important adaptation for long-distance flights. Increased reliance on fatty acids may spare carbohydrates and thus aid in maintenance of carbohydrate homeostasis.

This study was supported by NSF grant DEB 76-21376 for support of doctoral research, a dissertation grant from the Horace H. Rackham School of Graduate Studies, and NSF grant DEB 77-25487 to W.R. Dawson. W.R. Dawson provided space, equipment, criticism and encouragement throughout this study. D.W. Iohnston provided space in his laboratory and solved numerous logistical problems during my stay at the University of Florida. J. Allen, K. Guthe, J. Pringle, and C. Yocum of The University of Michigan and F. Davis, G. Stein, and S. Zam at the University of Florida provided access to equipment and materials under their care. I thank J. B. Odenheimer for extensive editorial assistance, and J.W. Cummings, S.J. Wickler, M.M. Martin, J.A. Faulkner, K.F. Guthe, and R.W. Storer for comments on early drafts of the manuscript.

\section{References}

Alp PR, Newsholme EA, Zammit VA (1976) Activities of citrate synthase and $\mathrm{NAD}^{+}$-linked and $\mathrm{NADP}^{+}$-linked isocitrate dehydrogenase in muscle from vertebrates and invertebrates. Biochem J 154:689-700

American Ornithologists' Union Committee on Classification and Nomenclature (1957) Checklist of North American birds. Lord Baltimore Press, Baltimore, MD

Andersen P, Henriksson J (1977) Capillary supply of the quadriceps femoris muscle of man : adaptive response to exercise. J Physiol (London) 270:677-690

Baldwin KM, Cheadle WG, Martinez OM, Cooke DA (1977) Effect of functional overload on enzyme levels in different types of skeletal muscle. J Appl Physiol 42:312-317

Bass A, Brdiczka D, Eyer P, Hofer S, Pette D (1969) Metabolic differentiation of distinct muscle types at the level of enzymatic organization. Eur J Biochem 10:198-206 
Beenakkers AMT (1969) Carbohydrate and fat as fuel for insect flight: a comparative study. J Insect Physiol 15:353-361

Beenakkers AMT, Dewaide JH, Henderson PT, Lutgerhorst A (1967) Fatty acid oxidation and some participating enzymes in animal organs. Comp Biochem Physiol 22:675-682

Berger M, Hagg SA, Goodman MM, Ruderman NB (1976) Glucose metabolism in perfused skeletal muscle: effects of starvation, diabetes, fatty acids, acetoacetate, insulin, and exercise on glucose uptake and disposition. Biochem J 158:191-202

Bergström J, Hultmann E (1967) A study of the glycogen metabolism during exercise in man. Scand J Clin Lab Invest 19:219 288

Berthold P (1975) Migration, control and metabolic physiology. In: Farner DS, King JR (eds) Avian biology, vol 5. Academic Press, New York, pp 77-128

Caldwell LD, Odum EP, Marshall SG (1963) Comparison of fat levels in migrating birds killed at a central Michigan and a Florida Gulf Coast television tower. Wilson Bull 75:428434

Carey C, Dawson WR, Maxwell LC, Faulkner JA (1978) Seasonal acclimatization to temperature in cardueline finches. II. Changes in body composition and mass in relation to season and acute cold stress. J Comp Physiol 125:101-113

Crabtree B, Newsholme EA (1972a) The activities of phosphorylase, hexokinase, phosphofructokinase, lactate dehydrogenase, and the glycerol-3-phosphate dehydrogenases in muscles from vertebrates and invertebrates. Biochem $\mathrm{J}$ 126:49-58

Crabtree B, Newsholme EA (1972b) The activities of lipases and carnitine palmitoyltransferase in muscles from vertebrates and invertebrates. Biochem J 130:697-705

Crabtree B, Newsholme EA (1975) Comparative aspects of fuel utilization and metabolism by muscle. In: Usherwood PNR (ed) Insect muscle. Academic Press, New York, pp 405-500

Fry CH, Ash JS, Ferguson-Lees IJ (1970) Spring weights of some palaearctic migrants at Lake Chad. Ibis 112:58-82

Fry CH, Ferguson-Lees IJ, Dowsett RJ (1972) Flight muscle hypertrophy and ecophysiological variation of the yellow wagtail Motacilla flava races at Lake Chad. J Zool (London) 167:293306

George JC, Berger AJ (1966) Avian myology. Academic Press, New York

George JC, Talesara CL (1961) The succinic dehydrogenase levels of the pectoral muscles of a few representative types of birds and a bat in relation to the fiber diameter, muscle weight, and body weight. Comp Biochem Physiol 3:267-273

George JC, Vallyathan NV (1964) Capacity for fatty acid oxidation by the breast muscle of the starling (Sturnus roseus) in the pre- and post-migratory periods. Can J Physiol Pharmacol $42: 447-452$

Gonyea W, Bonde-Petersen F (1978) Alteration in muscle contractile properties and fiber composition after weight-lifting exercise in cats. Exp Neurol 59:75-84

Hansford RG (1978) Lipid oxidation by heart muscle mitochondria from young adult and senescent rats. Biochem J 170:285-295

Henriksson J (1977) Training induced adaptation of skeletal muscle and metabolism during submaximal exercise. J Physiol (London) $270: 661-675$
Hochachka PW, Neely JR, Driedzic WR (1977) Integration of lipid utilization with Krebs cycle activity in muscle. Fed Proc $36: 2009-2014$

Holloszy IO, Booth FW (1976) Biochemical adaptations to endurance exercise in muscle. Ann Rev Physiol 38:273-291

Lighthill $\mathbf{J}$ (1977) Introduction to the scaling of aerial locomotion. In: Pedley TJ (ed) Scale effects in animal locomotion. Academic Press, New York, pp 365-404

MacDougall JD, Sale DG, Moroz JR, Elder GCB, Sutton JR, Howald H (1979) Mitochondrial volume density in human skeletal muscle following heavy resistance training. Med Sci Sports $11: 164-166$

Mansour TE (1966) Phosphofructokinase. II. Heart muscle. In: Wood WA (ed) Methods in enzymology, vol IX, Carbohydrate metabolism. Academic Press, New York, pp 430-436

Marsh RL (1979) Seasonal adjustments in size and biochemistry of the flight muscles in a long distance migrant, the gray catbird (Dumetella carolinensis). Ph D Diss University of Michigan, Ann Arbor

Molé PA, Oscai LB, Holloszy JO (1971) Adaptation of muscle to exercise. Increase in levels of palmityl CoA synthetase, carnitine palmityltransferase, and palmityl CoA dehydrogenase, and in the capacity to oxidize fatty acids. J Clin Invest 50:2323-2330

Newsholme EA, Start C (1973) Regulation in metabolism. Wiley, New York

Opie LH, Newsholme, EA (1967) The activities of fructose 1, 6 diphosphatase, phosphofructokinase, and phosphoenolpyruvate carboxykinase in white muscle and red muscle. Biochem J 103:391-399

Oscai LB, Molé PA, Holloszy JO (1971) Effects of exercise on cardiac weight and mitochondria in male and female rats. Am J Physiol 220:1944-1948

Paul P, Holmes WL (1975) Free fatty acid and glucose metabolism during increased energy expenditure and after training. Med Sci Sports 7:176-184

Pennycuick CJ (1975) Mechanics of flight. In: Farner DS, King JR (eds) Avian biology, vol 5. Academic Press, New York, pp $1-75$

Rennie MJ, Johnson RH (1974) Alteration of metabolic and hormonal responses to exercise by physical training. Eur J Appl Physiol 33:215-226

Srere PA (1969) Citrate synthase. In: Lowenstein JM (ed) Methods in enzymology, vol XIII, Citric acid cycle. Academic Press, New York, pp 3-11

Staudte HW, Pette D (1972) Correlations between enzymes of energy-supplying metabolism as a basic pattern of organization in muscle. Comp Biochem Physiol 41 B:533-540

Stevenson HM (1957) The relative magnitude of the trans-Gulf and circum-Gulf spring migrations. Wilson Bull 69:39-77

Williams JN, Jr, Thorp SL (1969) Re-evaluation of cytochrome $c$ concentrations in rat organs using a new method for cytochrome $c$. Biochem Biophys Acta 189:25-28

Williams TC, Williams JM, Ireland LC, Teal JM (1977) Autumnal bird migration over the Western North Atlantic Ocean. Am Birds 31:251-267

Williamson JR (1979) Mitochondrial heart function. Ann Rev Physiol 41:485-506 